\title{
REESTRUTURAÇÃO PRODUTIVA, REFORMA ADMINISTRATIVA DO ESTADO E GESTÃO DA EDUCAÇÃO
}

\author{
Elma Júlia Gonçalves de Carvalho*
}

\begin{abstract}
RESUMO: A proposta, neste texto, é identificar a relação entre o "novo modelo" de gestão empresarial e o modelo de gestão pública, denominado gerencial. Ressaltam-se também as repercussões desse modelo na organização administrativa da escola, que passa a ser caracterizada como democrática, participativa e descentralizada. $\mathrm{O}$ objetivo do texto é despertar no leitor a necessidade de atentar para o significado mais profundo das mudanças na forma de administrar a educação e a escola, especialmente a partir dos anos de 1990.

Palavras-chave: Gestão empresarial. Gestão pública. Gestão educacional. Gestão democrática.
\end{abstract}

\section{Productive re-Structuring, State administration reform AND EDUCATIONAL MANAGEMENT}

ABSTRACT: The relationship between the "new model" of enterprising management and the governmental management model or managerial model is identified. Repercussions of the managerial model in the school's administrative organization are highlighted due to the fact that it consequently becomes characterized as democratic, participatory and decentralized. Current research aims at making the reader aware of the need to reflect on the meaning of changes which have been experienced since the 1990s with regard to the manner school and education are managed.

Key words: Enterprising management. Government management. Educational management. Democratic administration.

Doutora em Educação e professora do Departamento de Teoria e Prática da Educação da Universidade Estadual de Maringá (UEM/PR).E-mail: elmajulia@hotmail.com 


\section{Introdução}

$\mathcal{E}$

ntendendo que as novas orientações ocorridas no campo empresarial oferecem elementos esclarecedores para se compreender os novos rumos da organização e gestão da administração pública, pretende-se, neste texto, evidenciar os principais aspectos do novo modelo, denominado gerencial, e analisar suas repercussóes na educação.

O texto, dividido em três partes, contempla: uma abordagem das mudanças administrativas e organizacionais no setor produtivo, uma análise das mudanças ocorridas na forma de administração pública e da redefinição do papel do Estado em geral e algumas reflexões sobre as repercussões das novas tendências de gestão administrativa no campo escolar, especialmente na educação básica, reconhecida legalmente como um direito de todos e dever do Estado.

Reestruturação produtiva: a substituição do modelo taylorista/ fordista pelo modelo de produção flexível

A partir do final da década de 70 do século Xx, o capitalismo mundial enfrentou um novo período de crise, identificada, sobretudo, como de esgotamento do modelo de acumulação taylorista/fordista, da administração keynesiana e do Estado de bem-estar social. Hobsbawn (1997, p. 19) considera que "a crise afetou várias partes do mundo de maneiras e graus diferentes, mas afetou todas elas, fossem quais fossem suas configuraçōes políticas, sociais e econômicas". As diferentes formas de enfrentá-la resultaram em um novo estágio do capitalismo mundial, cujas características são a mundialização ou transnacionalização do capital, a financeirização da economia, a reorganização produtiva de bases flexíveis, a remodelação da estrutura de poder e as novas formas de organização e gestão, tanto no setor privado quanto no público.

A profunda recessão econômica e o aumento nas pressões competitivas internacionais levaram as empresas, de um lado, a buscar espaços mais amplos de acumulação, definindo-se, assim, a chamada globalização da economia, ${ }^{1}$ e, de outro, a reestruturar e reorganizar a produção, criando o padrão de acumulação flexivel.

Segundo Harvey (2000, p. 140), a acumulação flexível, que se opõe à rigidez do sistema fordista, apoia-se na “(...) flexibilidade dos 
processos de trabalho, dos mercados de trabalho, dos produtos e dos padrões de consumo. Caracteriza-se pelo surgimento de setores da produção inteiramente novos, novas maneiras de fornecimento de serviços financeiros, novos mercados e, sobretudo, taxas altamente intensificadas de inovação comercial, tecnológica e organizacional”. Pode, assim, atender a uma gama bem mais ampla de necessidades do mercado, incluindo as rapidamente cambiáveis.

Sennett (2000) identifica três aspectos estruturais e organizacionais na moderna forma de flexibilidade dos processos de trabalho: a especialização flexível da produção, a reinvenção descontínua das instituições e a concentração do poder sem centralização.

Ele define a especialização flexivel como a tentativa de colocar produtos mais variados no mercado, respondendo com maior rapidez às instáveis demandas de consumo. A produção em massa dos bens homogeneizados, próprios do fordismo, é substituída pela produção de bens em pequenos lotes diferenciados, de forma a contemplar os consumidores individuais. Com efeito, os processos de produção de base rígi$\mathrm{da}$, operando em imensas linhas de montagem, com grandes estoques de produtos duráveis, envolvendo uma potenciação imensa do trabalho manual e desenvolvendo-se numa lógica de adestramento, vão dando lugar aos processos de base modular e produção enxuta. $\mathrm{O}$ ataque à rotina padronizada desmantelou a velha linha de montagem, substituindo-a por ilhas de produção isoladas, fragmentando e dispersando todas as esferas e etapas da produção, introduzindo processos flexíveis - "flextempo" -, horários flexíveis, trabalho domiciliar, trabalho por tarefas.

Essa forma de produção exige, ainda, rápidas tomadas de decisão e dá origem ao que Sennett denomina reinvenção descontínua das instituiçôes. Segundo ele, a prática administrativa moderna é pautada em redes mais abertas à reinvenção das hierarquias piramidais, isto é, substituem-se as hierarquias verticais, rígidas e claramente definidas por redes mais frouxas. O gerenciamento descentralizado implica o desaparecimento da figura do supervisor, permite que os trabalhadores tenham maior controle sobre suas próprias atividades e tende a adotar modelos de organização cooperativa e discursiva, em cujas tomadas de decisão os trabalhadores são envolvidos. Conclui, assim, que a tecnologia, aliada à flexibilização, vem desmantelando as antigas estruturas 
burocráticas de poder e que o novo princípio fundamental é o da "autorregulação". Segundo ele, ao trabalhador é atribuída maior responsabilidade pela sua própria eficiência, produtividade ou permanência no trabalho - liberdade/autonomia para controlar seu próprio trabalho. A internalização do controle é combinada com a responsabilização do grupo pela consecução das metas na célula da produção.

Assim, por exemplo, conforme Fleury e Vargas (1983, p. 35-36), "o grupo recebe uma tarefa com baixo nível de detalhamento, recebe recursos para executá-la e tem autonomia para se estruturar durante o processo de desenvolvimento do trabalho (...) as tarefas de planejamento e controle são entregues aos próprios elementos do grupo". Ou seja, as equipes de projetos ou forças-tarefas, reunidas para resolver questôes específicas ou problemas de curto prazo, têm a liberdade de cumprir as metas da maneira que julgarem mais adequada.

A terceira característica do regime flexível é a concentração de poder sem centralização. Para Sennett, os aspectos anteriores impóem a necessidade de uma nova forma de administração. A autoridade burocrática é substituída pela autonomia democrática, cujo gestor não mais centraliza o poder, mas coordena e agiliza a tomada de decisões por parte das equipes de trabalho.

Nessa nova lógica empresarial, o gerenciamento e a liderança são as chaves para a vantagem competitiva. O novo líder é aquele que tem capacidade de influenciar as pessoas: sua tarefa não é ditar normas, mas organizar as açōes, trabalhar na diversidade, conviver com outras opiniôes e estabelecer trocas mútuas. É um "administrador do processo", ou seja, seu papel é "(...) 'facilitar' uma solução entre o grupo e 'mediar' entre cliente e equipe (...)” (Sennett, 2000, p. 129).

Portanto, a flexibilização expressa uma mudança na forma do trabalho. A racionalidade técnica, burocrática e normativa é substituída por competências de interação e responsabilidade pessoal, que tornam o trabalho mais funcional, ajustando-o às incessantes mudanças de uma sociedade cada vez mais competitiva, exigente e sujeita a imprevistos. O trabalho em grupo, a cooperação, a participação, a autonomia e a gestão descentralizada do trabalho tornaram-se aspectos relevantes para a prática administrativa moderna. Dissemina-se a ideia de que estes aspectos contribuem para as modificações na posição do trabalhador dentro da empresa e para a democratização das relaçóes de trabalho. 
Para o autor, isto muda radicalmente a estrutura de poder dentro da empresa: desaparece a autoridade centralizada, dando lugar ao "exercício flexível de poder" (idem, p. 137), ou seja, à horizontalidade do poder de decisão e à atribuição de cargos mais fluida. ${ }^{2}$

No entanto, a ênfase na ideia de democratização não significa que dentro da empresa o controle esteja desaparecendo, mas sim que ele está sendo reajustado. A maior flexibilidade na organização do trabalho não significa necessariamente maior liberdade para o trabalhador. Pelo contrário, representa formas mais sutis de centralização, controle e regulação dos processos de trabalho, como o monitoramento por meios eletrônicos (e-mails, celulares, computação móvel, intrarredes de comunicação), denominados por Lima (1994, p. 120) de neotaylorismo ou taylorismo informático. Na verdade, o que se verifica na prática é que, fisicamente, o trabalho é descentralizado, mas o controle sobre o trabalhador é mais direto. Ao mesmo tempo, a contestação da velha ordem burocrática não significou a adoção de menor estrutura institucional. Ou seja, o que se verifica é a reinvenção da burocracia, por meio da concentração sem centralização.

É importante ressaltar que estas mudanças organizacionais caracterizam uma tendência, mas não atingem todos os setores da produção, e aplicam-se apenas a um grupo de trabalhadores. Ao lado de trabalhadores flexiveis ainda subsistem trabalhadores nos moldes tradicionais do taylorismo/fordismo. Ao lado das maciças fusões e diversificações corporativas, mantêm-se pequenos negócios e estruturas organizacionais de tipo artesanal doméstico, familiar, paternalista, cujos mecanismos de controle do trabalho são distintos. Com efeito, o que existe na prática são estratégias tayloristas/fordistas e flexíveis ou a combinação entre ambas.

Estas novas características da gestão não significam apenas novas formas de organização das empresas, em face da competição inerente à nova economia de mercado. Elas também revelam que as novas formas de os homens se pensarem e se organizarem socialmente condicionam as demais formas de organização política e social da atualidade e compelem os indivíduos a buscar autonomia pessoal diante das estruturas coletivas, baseadas no valor normativo das tradiçôes ou do poder do Estado, e a se desvincular das lealdades institucionais. Desse ponto de vista, o comprometimento com os desejos individuais de consumo, de 
propriedade e de liberdade individual, a opção pela apologia crescente da autonomia, da liberdade de fazer escolhas, de realizar seus interesses particulares e o desprezo pela ética geral ou princípios coletivos são manifestaçōes das novas condiçôes de existência humana. Isso significa que os avanços tecnológicos e a flexibilização dos processos produtivos definem não apenas novas formas de organização e gestão do trabalho, novos padrões de vida e de relacionamento, mas também novos papéis para as instituições.

Assim, é inerente a esse processo de reestruturação produtiva um movimento de "reinvenção" dos poderes e das funçōes do Estado, cujas repercussōes abrangem o campo educacional. Cabe, portanto, discutir alguns dos aspectos principais que caracterizam a nova tendência da atuação estatal.

\section{A "reinvenção" do Estado}

Os novos padrões de concorrência capitalista internacional, decorrentes da globalização, desencadearam um agudo processo de concentração e centralização de capitais e uma reorganização interna dos processos produtivos. Ao mesmo tempo, tiveram repercussões políticas e levaram o Estado a redefinir seu papel e suas funçōes.

Os desafios da globalização, aliados à crise do Estado, ${ }^{3}$ determinaram que, desde a década de 1980, o antigo Estado keynesiano ou do bem-estar consolidado no pós-guerra fosse gradativamente substituído pelo chamado Estado-mínimo. Seu papel passa a ser o de cuidar dos direitos de propriedade e reforçar os contratos privados, deixando ao mercado a responsabilidade de, por si só, promover a distribuição de benefícios, rendas e salários e garantir o bem-estar geral (Friedman, 1988).

Porém, na década de 1990, os defensores do modelo da gestão pública gerencial reconhecem os limites do neoliberalismo. O Estado passa a ser discutido não apenas sob o impacto das críticas às políticas de liberalização e privatização, mas também dos resultados decepcionantes alcançados por meio delas. A discussão engloba o modelo de Estado social-liberal e a administração pública gerencial como alternativas para o Estado-providência e para a administração burocrática. $\mathrm{O}$ que se apresenta é uma terceira via, ${ }^{4}$ cujas propostas se diferenciam tanto 
das teorias de esquerda (socialismo-comunismo) como das políticas de direita (liberalismo).

Nessa nova fase, parte-se da ideia de que, no capitalismo global, a presença do Estado é imprescindível, motivo pelo qual lhe é atribuída outra qualidade, e defende-se a reinvenção ou a reforma do Estado. Os componentes básicos da reforma do Estado dos anos de 1990, segundo Bresser Pereira (1997, p. 18-19), são:

(a) a delimitação das funções do Estado, reduzindo seu tamanho em termos principalmente de pessoal através de programas de privatização, terceirização e "publicização" (este último implicando na transferência para o setor público não-estatal os serviços sociais e científicos que hoje o Estado presta); (b) a redução do grau de interferência do Estado ao efetivamente necessário através de programas de desregulação que aumentam o recurso aos mecanismos de controle via mercado, transformando o Estado em um promotor da capacidade de competição do país em nível internacional, ao invés de protetor da economia nacional contra a competição internacional; (c) o aumento da governança do Estado, ou seja, da sua capacidade de tornar efetivas as decisões do governo, através do ajuste fiscal, que devolve autonomia financeira ao Estado, da reforma administrativa rumo a uma administração pública gerencial (ao invés de burocrática) e a separação, dentro do Estado, ao nível das atividades exclusivas do Estado, entre a formulação de políticas públicas e a sua execução; e, finalmente (d) o aumento da governabilidade, ou seja, do poder do governo, graças à existência de instituição políticas que garantam uma melhor intermediação de interesses e tornem mais legítimos e democráticos os governos, aperfeiçoando a democracia e abrindo espaço para o controle social ou democracia direta.

Nessa reforma, na perspectiva de seus proponentes, o Estado deve responder com maior rapidez e eficiência às constantes mutaçóes do mercado global e às demandas sociais, exercer um papel mais decisivo na reestruturação produtiva e diversificar as fontes de financiamento. Vê-se na reforma a possibilidade de se flexibilizar a ação estatal e de se liberar a economia, conduzindo-a a um novo ciclo de crescimento econômico e, ao mesmo tempo, proporcionar ao Estado maior governabilidade. Em face disso, o problema da eficácia administrativa torna-se questão central nos debates e nas reformas políticas dos anos de 1990 , em meio aos quais o novo modelo de gestão pública que se apresenta é o gerencial. 


\section{A administração pública gerencial}

O modelo gerencial tem influenciado as reformas administrativas de diversos países, redirecionando as formas de intervenção do Estado e da gestão das políticas públicas. Este modelo tem por base as propostas do New Public Management e Reinventing Government, conjunto de doutrinas globalmente semelhantes que, ao importar princípios e práticas da gestão empresarial, tem redefinido o conceito de gestão pública, com implicações para a gestão educacional.

O novo conceito envolve uma modificação profunda do modelo burocrático weberiano (organização guiada por procedimentos rígidos, forte hierarquia, organização burocrática, centralização das decisões, unidade de mando e delimitação nítida da esfera pública em relação à privada), em favor de organizaçōes mais flexíveis, da administração descentralizada, autônoma e participativa e da redefinição das relações entre esferas públicas e privadas.

Nesse novo modelo de gestão pública, com repercussões profundas na gestão educacional, a administração pública gerencial é orientada pelas estratégias de:

- limitar seus esforços à organização da produção de bens e serviços, deixando de prestá-los diretamente;

- estimular soluções fora do setor público, em geral, terceirizando, estabelecendo parcerias e contratando serviços no mercado;

- favorecer a participação crescente do trabalho voluntário e do "terceiro setor" na provisão dos serviços públicos; 5

- atuar como regulador e normatizador; separar a direção/ gerenciamento das políticas da prestação/execução de serviços;

- inventar novos sistemas orçamentários para a aquisição de recursos, como, por exemplo, a concessão de subsídios e premiação para instituições que obtiverem melhores resultados;

- eliminar entraves burocráticos, orientando-se por projetos, missōes ou tarefas, focalizando os resultados/fins desejados ao invés de se concentrar no processo/meios e na obediência a regras e regulamentos; 
- dar liberdade aos diferentes escalóes para escolher os métodos mais apropriados ao cumprimento de metas pré-fixadas, dotando-os de autonomia e favorecendo a máxima flexibilidade para aumentar a rapidez das respostas às circunstâncias cambiantes e imprevistas;

- exercer influência por persuasão e incentivos, sem usar comandos;

- controlar e fiscalizar o desempenho dos serviços prestados, adotando mecanismos de avaliação da satisfação do cliente;

- atuar de forma preventiva;

- descentralizar, atribuindo responsabilidades ao poder local (estados e municípios) e aos cidadãos, em lugar de simplesmente servi-los;

- promover o gerenciamento com participação, aprofundando a democracia direta, a fim de estimular a sociedade civil a ter mais iniciativa e capacidade de decisão para resolver seus próprios problemas;

- privilegiar os mecanismos do mercado (competição, livre escolha, opção do consumidor, tomadas de decisão baseadas nos melhores resultados);

- estruturar o mercado (estabelecer regras, orientar as decisões dos agentes privados) e induzi-lo a mudanças (divulgar informaçōes sobre a qualidade dos serviços, estimular a demanda, catalisar a formação de novos setores do mercado e conceder incentivos para influenciar a oferta de preços e serviços);

- abrandar ou reverter o crescimento do setor administrativo, diminuindo as despesas públicas e o número de funcionários; informatizar os serviços públicos; investir na transparência na administração e maior flexibilidade.

- redefinir seus usuários como clientes/consumidores, oferecendo-lhes opçōes e serviços para sua livre escolha; concentrar-se na identificação e atendimento de suas necessidades e preferências particulares (Osborne \& Goebler, 1998). 
No Brasil, o projeto de reforma ${ }^{6}$ do Estado, consubstanciado no Plano Diretor da Reforma do Aparelho do Estado (1995), pautou-se nesses princípios do modelo gerencial. Sua implantação abriu espaço para mudanças organizacionais e administrativas que repercutiram substancialmente na educação, especialmente no campo da gestão dos sistemas de ensino e das escolas, conforme aspectos analisados a seguir.

\section{A reforma do aparelho do Estado brasileiro e a nova tendência da gestão educacional}

As reformas na educação brasileira, a partir de meados da década de 1990, tiveram por base a nova forma de gerenciamento, que redefiniu o modo de organização, financiamento e gestão dos sistemas de ensino e das unidades escolares. A seguir, iremos relacionar aspectos do modelo gerencial com a gestão da educação, tomando por referência leis, projetos e programas governamentais que materializam essa nova orientação.

De acordo com o modelo gerencial, o Estado deixa de ser investidor e mantenedor, eximindo-se da responsabilidade direta de produzir e fornecer bens ou serviços e assumindo o papel de regulador e facilitador da iniciativa privada. Pressupóe-se, portanto, que ele seja árbitro, não parte, pois sua intervenção consiste em redistribuir ou realocar recursos, em introduzir regras orientadoras das relaçóes entre os prestadores públicos e privados, em avaliar previamente necessidades e recursos disponíveis, em definir antecipadamente metas e posteriormente monitorar sua realização. Separa-se, assim, a função de governar e a de executar.

Esta separação permite que o Estado faça concessão de serviços, introduzindo mecanismos externos de contratação, transferindo, para as instituiçōes privadas ou públicas não-estatais, ${ }^{7}$ na qualidade de prestadoras, funçōes e serviços tradicionalmente desempenhados por ele ou estabelecendo parcerias com a sociedade. Ele cria, assim, um ambiente que pode favorecer a competiçáo e, ao mesmo tempo, a atuação do cidadão/comunidade nos negócios públicos (Brasil/MARE, 1995, p. 55). Esta é uma estratégia para enfrentar a falta de recursos decorrente do déficit fiscal do Estado. Além disso, procura ampliar a atuação de agentes privados em espaços antes considerados exclusivamente públicos, submetendo-os às regras do mercado. 
Restringir o Estado à função de regulação e de catalisação implica levar a sociedade ou os indivíduos a agirem por si mesmos na busca de solução para seus problemas. Implica também aumentar a participação social em atividades que antes eram de sua exclusiva competência. ${ }^{8}$ Por isso, estimula-se constantemente a busca de soluçôes fora do setor público, por meio de agências autônomas ou "organizaçôes sociais", " da cooperação voluntária da comunidade e da co-parceria com a iniciativa privada na consecução dos objetivos públicos, introduzindose, ao mesmo tempo, uma nova proposta de regulação social, sustentada na participação.

É o que se observa no programa "Acorda, Brasil" (1995) e no projeto "Amigos da Escola" (1999), lançados no governo Fernando Henrique Cardoso. Estas iniciativas, cujo objetivo central é mobilizar a sociedade para assumir compromissos em relação à escola pública, são exemplos dessa nova tendência. Ambas incentivam empresas, entidades, prefeituras, comunidades e cidadãos em geral a realizar parcerias com o poder público em benefício da escola. A sociedade é conclamada a adotar escolas, contribuir para seu bom funcionamento, patrocinar a compra ou fazer doações do que for necessário à manutenção do prédio, ao aparelhamento da unidade escolar, ao enriquecimento da merenda escolar, ao aprimoramento da atividade docente, ao desenvolvimento da aprendizagem dos alunos. O "Acorda, Brasil" prevê ainda a distribuição de verbas federais diretamente às escolas, sem a intermediação dos governos estaduais e municipais, a reforma do currículo e a avaliação das escolas, por meio de testes aplicados aos alunos, com premiação daqueles que apresentarem melhor desempenho (MEC-CNI/ SENAI/SESI/IEL, 1995).

Como referência mais recente, temos o Plano de Desenvolvimento da Educação (PDE, 2007), lançado no Governo Lula. Para operacionalizar o Plano, o governo federal baixou o Decreto n. 6.094, em 24 de abril de 2007, que "dispõe sobre a implementação do Plano de Metas Compromisso Todos pela Educação, pela União Federal, em regime de colaboração com Municípios, Distrito Federal e Estados, e a participação das famílias e da comunidade, mediante programas e ações de assistência técnica e financeira, visando a mobilização social pela melhoria da qualidade da educação básica". De acordo com o documento, cabe aos diferentes sistemas de ensino, entre outras atribuiçốes: promover a gestão participada; elaborar plano de educação e instalar 
Conselho de Educação; acompanhar e avaliar, com a participação da comunidade e do Conselho de Educação, as políticas na área da educação; fomentar e apoiar os conselhos escolares, envolvendo as famílias dos educandos na atribuição de zelar pela manutenção da escola e pelo monitoramento das açôes e consecução das metas do compromisso; firmar parcerias externas à comunidade escolar, visando à melhoria da infraestrutura da escola ou à promoção de projetos sócio-culturais e ações educativas.

Outro exemplo da nova forma de atuação do Estado é o Fundo de Manutenção e Desenvolvimento do Ensino Fundamental e de Valorização do Magistério (FUNDEF, instituído pela Emenda Constitucional n. 14, de 12 de setembro de 1996, e regulamentado pela Lei n. 9.424, de 24 de dezembro do mesmo ano, e pelo Decreto n. 2.264, de 27 de junho de 1997 foi implantado em $1^{\circ}$ de janeiro de 1998), substituído pelo Fundo de Manutenção e Desenvolvimento da Educação Básica e de Valorização dos Profissionais da Educação (Fundeb, Lei n. 11.494, de 20 de junho de 2007). Ao abandonar as funçóes mantenedoras, a União preserva a função supletiva e redistributiva, ou seja, ao governo federal cabe apenas completar, com seus recursos, o financiamento da educação básica, de competência dos estados e municípios, sempre que os recursos destes forem insuficientes, oferecendo uma garantia mínima de financiamento para este nível de ensino.

Uma forma de subvenção estatal na educação tem sido o subsídio por aluno, ou seja, o financiamento proporcional ao número de matrículas, conforme estabelecido pelo FUndeB (2007) e pelo Programa Direito Direto na Escola (PDDE, 1995). Neste caso, de acordo com o modelo gerencial, os recursos alocados dependem da demanda e de uma constante avaliação dos resultados.

De acordo com o modelo gerencial, o governo empreendedor deveria financiar os resultados e não simplesmente conceder recursos. Para isso, os governos devem adotar mecanismos de avaliação de desempenho e de aferição de rendimento, que, através de "ranking", classifiquem e tornem públicos os resultados. No sistema educacional, os indicadores de desempenho são obtidos por meio do Sistema de Avaliação da Educação Básica (sAEB), do Exame Nacional do Ensino Médio (ENEM) e do recém criado Índice de Desenvolvimento da Educação Básica (IDEB). ${ }^{10}$ Avaliação é feita por meio de testes individuais aplicados 
aos alunos por agentes externos à escola, com base nas matrizes curriculares validadas nacionalmente, os Parâmetros Curriculares Nacionais (PCN).

A avaliação, como instrumento de gestão educacional, não objetivaria somente o controle de resultados por parte do Estado, por meio do "estabelecimento de parâmetros para a comparação e classificação dos desempenhos, estímulo por meio de premiação, possibilidade de controle público do desempenho do sistema escolar" (Souza \& Oliveira, 2003, p. 881). Seria também um mecanismo para induzir à prestação de contas e à responsabilização pelos resultados alcançados, ou seja, um mecanismo para informar sobre a eficiência e produtividade dos serviços educacionais.

Em outros termos, na perspectiva gerencial, os governos deveriam recorrer mais a incentivos e menos à imposição de regulamentos. Nesse sentido, a avaliação representaria simultaneamente um importante instrumento de controle, regulação e fiscalização, ou seja, verificaria se as metas estabelecidas tinham sido alcançadas, esclareceria os "consumidores" sobre as escolas que merecessem ser consideradas como de qualidade, permitiria que "as forças do mercado" operassem com força total e que os indivíduos ficassem livres para efetuar escolhas; ao mesmo tempo, permitiria medir o rendimento dos investimentos educativos e levantaria indicadores para o repasse de verbas públicas.

O controle dos resultados é uma estratégia utilizada pela administração empreendedora para orientar as decisões, alcançar as metas estabelecidas, estruturar o mercado educacional para garantir as demandas sociais, sem criar burocracias administrativas no setor público, preservando a descentralização dos sistemas.

Assim, os mecanismos de avaliação, na perspectiva neoliberal, dariam voz e ouvidos aos clientes no controle dos serviços públicos, revitalizando a participação da comunidade; ao mesmo tempo, divulgando os resultados e premiando com maiores verbas e recursos as instituições que apresentassem melhor desempenho na escala avaliativa, estimulariam a responsabilização pelos resultados escolares e a competição entre as instituições.

A relação entre o modelo gerencial e a gestão da educação aparece também nos novos sistemas de controle criados pelo Estado. Em seu novo papel de regulador, ele recorre a empresas e agências de regulação 
ou, ainda, à "delegação de poderes" ao consumidor, pela avaliação direta, a fim de possibilitar um monitoramento mais efetivo do desempenho das burocracias e das agências prestadoras de serviços. O consumidor, entendido como o "indivíduo que paga pelos serviços que obtém do Estado", passa a ser considerado como um juiz mais competente na avaliação da qualidade dos serviços públicos (tempo, gasto, acessibilidade, rapidez dos resultados e custo), favorecendo a comparação de resultados e induzindo a concorrência entre as empresas públicas, semipúblicas e privadas.

Nesta direção, o Plano Diretor, visando promover o empowerment ${ }^{11}$ do cidadão, propõe que sejam criados "mecanismos que viabilizem a integração dos cidadãos ao processo de definiçãao, implementação e avaliação da ação pública” (Brasil/MARE, 1995, p. 51). Entre os mecanismos previstos, estão a "participação popular nos conselhos administrativos das agências públicas não-estatais" para a fiscalização e deliberação coletiva, através do controle social direto (idem, ibid., p. 55 e 58), e o "sistema de recebimento de reclamações e sugestôes dos cidadãos sobre a qualidade e eficácia dos serviços públicos” (p. 75), ou indicador direto de avaliação da satisfação do cliente.

No campo educacional, essa nova forma de controle pode ser identificada no "Fala, Brasil! - Serviço de Atendimento ao Cidadão". Trata-se de um serviço telefônico gratuito oferecido pelo MEC, para receber consultas, reclamações, denúncias e sugestões da população para o encaminhamento das questóes escolares.

No mesmo sentido, foram criados mecanismos de controle social, a exemplo do que é previsto no FUNDEB, ou seja, a obrigatoriedade de os estados, Distrito Federal e municípios criarem Conselhos (compostos por pais, professores, servidores de escolas públicas do ensino fundamental, Secretaria de Educação e entidade de classe), conforme inciso IV, $\mathbb{S} 1^{\circ}$, artigo $4^{\circ}$, da Lei n. 9394/96. A responsabilidade desses Conselhos é o acompanhamento e o controle sobre a repartição, transferência e aplicação dos recursos do Fundo na sua respectiva esfera de governo; a verificação dos registros contábeis e dos demonstrativos gerenciais; a supervisão do Censo Escolar anual; acompanhamento da aplicação dos recursos federais transferidos à conta do Programa Nacional de Apoio ao Transporte do Escolar (PNATE) e do Programa de Apoio aos Sistemas de Ensino para Atendimento à Educação de Jovens 
e Adultos. Sua função não é administrar os recursos do Fundo, responsabilidade que compete ao chefe do Poder Executivo e ao secretário da Educação, mas acompanhar toda a gestão desses recursos, garantindo sua destinação exclusivamente para a educação básica.

Para o modelo gerencial, a participação cidadã é entendida como um indicador dos gastos que serão desnecessários, dos programas governamentais que deverão ser cortados e dos que revelam eficiência, dos que devem ser subsidiados ou receber incentivos financeiros como recompensa pelos resultados ou pela maior produtividade. Isso desobriga os governos da tarefa de selecionar os programas passíveis de eliminação, de identificar que serviços devem ser prestados pelo setor privado, restringindo, pelo menos em tese, a autoridade conferida à burocracia e, ao mesmo tempo, evitando o descontentamento dos cidadãos que irão receber apenas os serviços que estão dispostos a pagar. A participação social também evitaria o conflito entre interesses particulares, uma vez que são os próprios cidadãos que definem o destino dos recursos públicos.

Portanto, o novo modelo de gestão pública, no campo educacional, caracteriza-se por novas formas e combinaçôes de financiamento, fornecimento, regulação e controle. A participação corresponde aos novos processos de regulação, cujas bases são as formas indiretas de controle, as novas condiçôes de exercício do poder e a reconfiguração dos papéis nas várias instâncias do sistema educativo. Por meio de outras fontes e instrumentos de regulação (Barroso, 2003), focalizam-se os fins desejados, caracterizando-se, assim, a passagem da estratégia de "regulação do controle" dos meios e procedimentos a priori para a da "regulação autônoma e sistêmica" a posteriori dos resultados (Brasil/ MARE, 1995, p. 22). É o caso da avaliação, que, ao analisar os objetivos por meio do controle do produto, e não dos processos, reduz a interferência do Estado no funcionamento das organizações escolares e nos comportamentos dos seus agentes, o que não significa maior autonomia, mas um controle mais sutil, sem comandos explícitos.

Para o modelo gerencial, o governo empreendedor deve privilegiar os mecanismos de mercado. No caso da educação, Osborne e Goebler (1998, p. 98, 109 e 115), em termos semelhantes aos de Friedman, afirmam: "a competição por estudantes e também por recursos" é a "ferramenta de revitalização da educação", o "elemento 
gerador de inovação". Por isso, a escola deve ser liberta do Estado e passar a ser gerida como empresa. Cria-se, assim, um referencial competitivo, ${ }^{12}$ que fornece aos pais possibilidade de escolha sobre o tipo de escola que desejam para seus filhos. Premiando as instituições bem sucedidas, oferecendo incentivos à produtividade e avaliando o desempenho, o Estado propõe um sistema educacional baseado na autonomia e na democracia. ${ }^{13}$

Embora a competição entre as escolas não esteja formalmente colocada como parte integrante das políticas públicas no Brasil, alguns dos mecanismos adotados acabam por incentivar a competição e a produtividade. Comandados pela Organização das Naçōes Unidas para a Educação, a Ciência e a Cultura (UNESCO), o Conselho Nacional dos Secretários em Educação (CONSED), a União Nacional de Dirigentes Municipais de Educação (UNDIME) e a Fundação Roberto Marinho criaram, em 1998, o "Prêmio Nacional de Referência em Gestão Escolar", cujo objetivo é estimular, através da competição entre as escolas públicas do ensino básico, com mais de cem alunos, a melhoria contínua de seus resultados.

Outro exemplo é o "Prêmio Professores do Brasil" (2005), que nasceu da unificação dos antigos "Prêmio Incentivo à Educação Fundamental" e "Prêmio Qualidade na Educação Infantil", também envolvendo pareceria do CONSED, UNDIME, Fundação Bunge e Fundação Orsa.

$\mathrm{O}$ modelo gerencial introduziu a gestão por projetos, identificada como a forma mais adequada de se eliminar custos desnecessários, desenvolver produtos e serviços correspondentes às inovações, às novas exigências dos diferentes clientes e à vantagem competitiva, além de criar uma estrutura organizacional flexível e integradora e uma maior cooperação entre pessoas, equipes e departamentos.

Este modelo, seguindo a adhocacia ${ }^{14}$ operacional, baseia-se na substituição de regras formais e instrumentos regulares de execução do trabalho por uma forma de gestão flexível, dirigida para a realização de metas e objetivos. Neste caso, os atores organizacionais, diretamente empenhados na realização do projeto, deverão contar com um clima organizacional dinâmico e cooperativo que favoreça a participação ativa e tomada de decisão.

Aplicado ao campo da educação, o sistema de gestão por projetos, a exemplo do projeto pedagógico, envolve a identificação da missão, 
dos objetivos, das metas e estratégias, de forma a tornar possível a responsabilização coletiva e/ou individual pela realização das tarefas e pelo controle operacional (monitorização do funcionamento e dos resultados).

$\mathrm{Na}$ perspectiva gerencial, a gestão autônoma do sistema educativo é concebida como capaz de gerar respostas adequadas à realidade de cada estabelecimento de ensino e de cada comunidade; é uma forma de assegurar a formação de uma identidade institucional e, ao mesmo tempo, o respeito à diversidade de interesses dos destinatários. Nesse sentido, a autonomia legitima a flexibilização organizacional do sistema, tornando-o capaz de assegurar uma diversificação/diferenciação da oferta, em face das diferentes necessidades e preferências e de aumentar a rapidez das respostas em circunstâncias cambiantes e imprevistas. Como se pode observar na LDB n. 9394/96 que, diferentemente das legislações anteriores, dá ênfase à descentralização, à autonomia das escolas e à participação da comunidade nos processos decisórios e flexibiliza a organização administrativa no interior das escolas.

Segundo o modelo gerencial, a eficácia ${ }^{15}$ só pode ser obtida por meio do abandono da centralização e da concentração de poderes, ou seja, permitindo que as pessoas que estão diretamente em contato com os problemas tenham cada vez mais iniciativa e capacidade de decisão. Por isso, a gestão, seja empresarial ou pública, passa a se apoiar em novos padrões, ou seja, na participação e nas formas coletivas de trabalho, nas quais se compartilham responsabilidades e poder. Em face disso, o novo líder é aquele cujo poder decorre da influência e não do mando.

Com base nos novos paradigmas, as políticas públicas atuais conferem ao administrador escolar uma importância estratégica. A descentralização operacional aumentou as responsabilidades da escola, levando seu gestor a se defrontar com novos desafios, assumir o papel de coordenador da ação dos diferentes componentes do sistema educacional na tomada de decisões conjuntas, estimular o trabalho em equipe e as dinâmicas de trabalho identificadas de sua escola e resolver seus problemas de forma autônoma. Ele torna-se o elemento central e fundamental para o encaminhamento do processo participativo no interior de sua escola e para sua integração com a comunidade.

A gestão da escola é, nesta perspectiva, catalisadora do movimento autônomo e co-responsável na gestão por resultados. A democratização 
dos processos administrativos no interior da escola exige que o gestor da escola seja capaz de influenciar, motivar, assumir, ao invés de impor ou só exigir, sendo sua ação identificada como um dos fatores determinantes do "sucesso" da escola. Assim, quanto mais disponibilidade tiver o gestor para partilhar responsabilidades, mais a gestão estará aberta à participação dos agentes envolvidos (professores, especialistas, alunos, funcionários e comunidade externa). Portanto, mais democrática e eficiente será considerada, seja na conquista e atendimento ao cliente e às demandas do mercado, seja na articulação de soluções e na aquisição de fontes suplementares de recursos.

No modelo gerencial, os governos, ao separar direção das políticas e prestação de serviços, delegam responsabilidades para o poder local. Por isso, o Plano Diretor garantiria, segundo seus proponentes, uma presença mais efetiva do Estado, especialmente no nível federal, mediante o aumento da centralização do planejamento e do controle e da descentralização da execução para os níveis estaduais e municipais (Brasil/MARE, 1995).

Na educação, esse aspecto é evidente no Planejamento PolíticoEstratégico, elaborado pelo MEC, no primeiro ano do governo FHC, para o quadriênio 1995-1998. O documento acentua sua importância para o desenvolvimento econômico e estabelece como desafio a "mobilização" da sociedade para enfrentar as distorçôes do sistema educacional brasileiro. Uma das estratégias é "retirar da Constituição os dispositivos que engessam o sistema educacional", instituindo "um novo Conselho Nacional de Educação, mais ágil, menos burocrático" (BRASIL/MEC, 1995 , p. 8), resguardando ao MEC o papel de "formulação, coordenação e acompanhamento de políticas públicas na área educacional e a consequente redução de seu papel executivo" (ibid., p. 4). Cabe ao MEC, segundo o documento, "um papel político-estratégico na coordenação da política nacional de educação". As funçōes do Ministério seriam "estabelecer rumos, diretrizes e fornecer mecanismos de apoio às instâncias estaduais ou municipais da administração pública e ao setor privado". São, portanto,

(...) os estados e municípios que efetivamente atuam no nível estratégicogerencial do sistema educacional, pois acompanham, avaliam, coordenam e integram o planejamento e os resultados alcançados pela escola. Aqui reside o ponto mais importante do sistema educacional, pois é exclusivamente na escola que os resultados podem ser alcançados. (Ibid., p. 5) 
Nesse aspecto, também não nos parecem diferentes os encaminhamentos dados à atual política educacional brasileira, especialmente no que diz respeito ao PDE (2007).

Observa-se também que, ao mesmo tempo em que as políticas educativas descentralizam os sistemas de ensino e estabelecem bases para a autonomia da gestão das instituições escolares, o Estado regulamenta, avalia e monitora as unidades escolares e mantém centralizadas as decisões relevantes. Os mais importantes meios de controle da educação são: a proposta de parâmetros curriculares nacionais (PCN), com base nos quais se realiza a avaliação de desempenho (ENEM, SAEB, IDEB); os critérios para a distribuição, a utilização e a fiscalização de recursos (FUNDEB); a avaliação do livro didático, que tende a recomendar textos que dialoguem com os PCN; a TV Escola, que dissemina uma programação afinada com os PCN; a criação de banco de dados informatizados e a prestação de contas dos recursos e dos resultados ou accountabitity $^{16}$ (PDE).

Nesse sentido, a reorganização do setor público tem-se pautado pelo que Sennett (2000) denominou de "reinvenção descontínua das instituiçôes". Este processo envolve novos mecanismos de controle, cujos resultados são a "despersonalização do poder" (Bruno, 1997) e a autonomia meramente operacional de participação controlada dos agentes educativos, não significando o controle das instâncias decisórias e de poder.

\section{Considerações finais}

Na década de 1980, descentralização, participação e autonomia passaram a ser princípios amplamente defendidos pelas forças políticas e pelos movimentos sociais que lutavam em prol da democratização política, especialmente nos países semiperiféricos governados pelas ditaduras militares.

$\mathrm{Na}$ década de 1990, vivenciou-se um processo de (re)significação destes princípios, por parte dos teóricos neoliberais, e de incorporação à reforma do Estado. A proposta de gestão democrática encaminhada nos anos 90 compunha-se de uma variedade de medidas que aparentemente visavam fortalecer a sociedade civil, uma vez que sugeriam que ela compartilhasse decisões. No entanto, sua finalidade 
era levar a comunidade a assumir a responsabilidade, o "ônus" pela resolução de seus próprios problemas. Ao mesmo tempo, essa forma de gestão aumentava as possibilidades de utilização do princípio de subsidiariedade, garantindo a apropriação do fundo público pelo capital privado e atendendo, pelo programa de "publicização", aos interesses expansivos do capital, cujo fim era investir sempre em novos setores.

Portanto, no atual estágio do capitalismo, essa racionalidade, empenhada em ampliar democraticamente a participação dos atores locais no processo educacional, encontra-se muito mais relacionada à sua responsabilização pela manutenção dos sistemas de ensino, em termos de financiamento (complementação orçamentária e mobilização de recursos adicionais). ${ }^{17}$ Ela redefine, assim, o conceito de participação, relacionando-o não ao sentido de cidadania participativa, mas ao de "participação-colaboração" ou "participação-coesão", ou seja, a "uma técnica de gestão para a promoção da eficácia e qualidade”, nos moldes empresariais (Lima, 1994, p. 131).

O novo modelo, ao distribuir competências, criou uma ambiguidade no que se refere à responsabilidade pela decisão, à definição das competências, à maior imprevisibilidade e à ausência de autoridade e consolidou um perfil "híbrido" dos serviços centrais. Nos termos deste artigo, considera-se que essa "despersonalização do poder" aumenta a responsabilidade das unidades escolares, distanciando-as dos governos centrais, re-situando e diminuindo o compromisso do poder público. Ao mesmo tempo, dá ênfase à maior participação da comunidade na gestão das instituições públicas, combinando democracia participativa e iniciativa autônoma com as novas formas de controle.

No entanto, embora este aspecto seja decisivo na definição do processo político "descentralizador" e "autonomizador", não é o único. Podemos dizer que os mesmos poderes que apelam para a participação dos atores sociais associam esta energia a dispositivos de privatização, semiprivatização e mercantilização dos serviços sociais.

Sob esta ótica, a proposta do governo de ampliar a participação da comunidade é uma forma de levar os cidadãos a fomentar o mercado de acordo com seus próprios valores e necessidades (Osborne \& Goebler, 1998). A cidadania se torna uma categoria predominantemente econômica, caracterizada principalmente pela liberdade de escolha, competição e iniciativa individual. Estes aspectos não só favorecem 
como também atribuem maior valor a mecanismos e critérios de mercado, como eficácia, produtividade, competitividade, consumismo individualista e satisfação dos interesses restritos. Tudo isso, em detrimento dos interesses sociais mais amplos e públicos ou de perspectivas coletivas, reconhecidas como comuns.

A prevalência da lógica do mercado tende, por um lado, a "empresariar" a educação, redefinindo as normas de qualidade, a concepção de interesse público e a relação dos pais com a escola, com base numa perspectiva consumista e individualista. Por outro lado, tende a deslocar a tomada de decisões sobre as questões educativas da "arena política”, que envolve interesses comuns de classe na composição das lutas coletivas, para o domínio privado, cujas bases são as escolhas individuais e interesses dos consumidores.

Os discursos gerencialistas consideram a escola uma empresa como qualquer outra. Consequentemente, veem a educação como um serviço que deve primar pela satisfação do cidadão enquanto clienteconsumidor individual, assegurando, como critério de eficiência, seu direito inalienável à qualidade dos serviços prestados.

Com efeito, ao reconceituarem os alunos como clientes, passam a respeitar suas escolhas individuais e subjetivas como referência orientadora das estratégias de adaptação organizacional para a sobrevivência e sucesso das organizações educativas. Por isso, segundo o modelo gerencial, a escola precisa da participação e parceria dos clientes para definir com clareza o que eles próprios desejam e, assim, definir os programas, formular e implantar seu próprio projeto pedagógico. Nesse processo, a escola se deixa guiar muito mais pelas demandas dos usuários do que por compromissos públicos, valores e regras comuns e interesses coletivos.

Para finalizar, importa ressaltar que a reforma do Estado, ao assimilar os modos de gerenciamento do setor privado, submeteu as instituições públicas à lógica do mercado (competição administrada, valorização do cliente consumidor, ênfase nos resultados, entre outros aspectos) e alterou seu funcionamento, sua organização e sua forma de gestão. Essas mudanças nos impóem o desafio de aprofundar a compreensão teórica desse processo e reavaliar a nossa própria atuação no interior das instituições educacionais.

Recebido em maio de 2008 e aprovado em julho de 2008. 


\section{Notas}

1. Segundo Fonseca (1997, p. 2), a globalização ocorrida no início dos anos de 1980 é resultado da junção de três forças poderosas: 1) a terceira revolução tecnológica (tecnologias ligadas à busca, processamento, difusão e transmissão de informações; inteligência artificial; engenharia genética); 2) a formação de áreas de livre comércio e blocos econômicos interligados (Mercado Comum Asiático, a União Europeia e o Nafta) - como uma nova forma de o capitalismo imperialista constituir mercados regionais cativos, mais amplos e fortemente protegidos; 3 ) a crescente interligação patrimonial e a interdependência dos mercados industriais e financeiros, em escala planetária, ou seja, não apenas entre as principais economias capitalistas, mas com participação também dos países socialistas.

2. Esta estrutura é típica da gestão por projetos ou de equipes temporárias de trabalho.

3. A crise do Estado é definida em três dimensôes: "(1) uma crise fiscal, caracterizada pela crescente perda de crédito por parte do Estado e pela poupança pública que se torna negativa; (2) como esgotamento da estratégia estatizante de intervenção do Estado, a qual se reveste de várias formas: o Estado do bem-estar social nos países desenvolvidos, a estratégia de substituição das importações no terceiro mundo e o estatismo nos países comunistas; e (3) como superação da forma de administrar o Estado, isto é, a superação da administração pública burocrática" (Brasil/MARE, 1995, p. 15).

4. Chauí (1999, p. 10) caracteriza a terceira via em suas diferentes instâncias: "a) Política: trata-se de um movimento de 'modernizar o centro', com a aceitação da idéia de justiça social e a rejeição da 'política de classes' e da igualdade econômica, procurando apoio em todas as classes sociais e assegurando que o governo seja uma das condiçóes para a expansão e o desenvolvimento da liberdade individual; b) Economia: trata-se de criar uma 'economia mista' que equilibre regulação e desregulação (...). Cabe ao Estado preservar a competição, quando ameaçada pelo monopólio (...); criar bases institucionais para os mercados, uma vez que estes dependem de grande acumulação de capital que não pode ser feita diretamente pelo mercado (...) saber enfrentar as catástrofes engendradas pelo mercado, estimulando a criação de 'empresas responsáveis'; c) Governo: (...) O principal problema para o Estado democrático é o de sua legitimidade, e esta só será reconquistada com uma reforma administrativa que torne o Estado um administrador tão competente como uma grande empresa. Por outro lado, (...) precisa democratizar-se e o fará operando por delegação de poder, referendos, plebiscitos, democracia direta nas localidades, transparência nos negócios públicos, em suma, por aumento da participação política com a estratégia de renovação e de incentivo à formação de comunidades solidárias; d) Nação (...) Trata-se, pois, de reinventar a nação num mundo cosmopolita como 'força estabilizadora e freio à fragmentação' e como 'condição do possível desaparecimento das guerras de grandes proporções entre os Estados'; e) Bem-estar social: trata-se de corrigir os excessos e efeitos perversos do Estado-providência (burocracia, comodismo, passividade, safadeza) e reformar o Estado de bem-estar, tendo como agentes os indivíduos e outros órgãos, que não o Estado, criadores de riqueza. A reforma reorientará o investimento social do Estado, estabelecendo um equilíbrio entre risco, seguridade e responsabilidade (individual e coletiva) e tendo como pilar o seguinte princípio: 'Investir em capital humano e não pagar diretamente os benefícios"”. No Brasil, a proposição da terceira via foi assumida explicitamente pelo governo Fernando Henrique Cardoso, a partir da aprovação do Plano Diretor da Reforma do Aparelho do Estado (Brasil/Mare, 1995).

5. O "terceiro setor", denominado não-governamental e não-empresarial, é portador de uma nova cultura de participação da sociedade civil e de promoção das políticas sociais. Com 
ele estamos presenciando o surgimento de uma esfera pública que não integra o aparelho estatal e de iniciativas privadas com "sentido público". Em outros termos, ocorre uma ruptura dos limites entre público e privado, os espaços se confundem e suas esferas de atuação não ficam claras. Essa indefinição dos limites de atuação do público e do privado dá margem a políticas com aparências modernizadoras, democráticas, de interesse social, mas que, em última instância, favorecem os objetivos da iniciativa privada e de desencargo do Estado, especialmente em relação às suas funções sociais (Carvalho, 2005).

6. A reforma do Estado, por ser um projeto amplo, envolveu várias áreas do governo, implicando mudanças no sistema jurídico-legal, tributário e fiscal, reforma previdenciária e reformas econômicas orientadas para o mercado (Brasil/MARE, 1995).

7. A expressão setor público não-estatal, de acordo com o PDRAE (Brasil/MARE, 1995), tem o sentido de se dedicar ao público e não-estatal, que não faz parte do aparelho do Estado, a exemplo das organizações sociais e agências executivas - autarquias e fundações. A suposta existência desse espaço intermediário, de natureza semipública e/ou semiprivada, representa, conforme Silva Jr. e Sguissardi (2000, p. 98), uma "redefinição das esferas pública e privada, que, no contexto de um Estado reformado, possibilitou a entrada do capital nesses espaços sociais, desencadeando sua reorganização conforme a lógica do privado". Para os autores, "tais dimensōes se movimentam indefinida e ambiguamente para criar a ilusória emergência desses espaços intermediários, quando, de fato, o que ocorre é uma clara redefinição dessas esferas diante da necessidade de expansão estrutural própria do capital" (p. 99).

8. Isso exige que os indivíduos tenham capacidade empreendedora, ou seja, criatividade, autonomia, discernimento, decisão e responsabilidade pessoal, de modo que eles próprios sejam agentes de mudança de seu destino e da comunidade de que fazem parte. Por isso, o Relatório Delors recomenda uma concepção de educação que, pautada em cinco pilares aprender a conhecer, aprender a fazer, aprender a viver juntos, aprender a viver com os outros, aprender a ser -, tenha por objetivo formar sujeitos que participem ativamente, por meio de projetos sociais, açôes humanitárias etc., de uma sociedade cuja participação solidária cresce em face do encolhimento do Estado.

9. O Projeto das Organizações Sociais tem por objetivo permitir a descentralização de atividades no setor de prestação de serviços não-exclusivos do Estado (que terão autonomia administrativa e financeira), transferindo a execução para o setor público não-estatal e mantendo o financiamento do Estado. Busca-se, também, a maior participação da sociedade, por meio de sua atuação nos conselhos de administração e parceria num regime de co-gestão.

10. O IDEB é um indicador cujo objetivo é "a verificação do cumprimento das metas fixadas no termo de Adesão ao Compromisso". Será calculado e divulgado periodicamente pelo INEP, com base nos dados sobre aprovação escolar, obtidos no Censo Escolar, e médias de desempenho de avaliação nas avaliações do INEP: O SAEB, para as unidades da federação e para o país, e a prova Brasil, para os municípios" (MEC, 2007, p. 5). O IDEB promove conexōes entre avaliação, financiamento e gestão.

11. O empowerment apresenta-se como um conceito relativamente recente. Pode ser entendido como o crescimento de poder, induzido ou conquistado, que permite aos indivíduos ter maior atuação nas políticas de regulação.

12. Uma modalidade radical implementada em alguns países, embora não se tenha consolidado no Brasil, é a concessão de "vales educacionais". Outra modalidade, também radical, é a "escola cooperativa" - ensino público, com microgestão privada - já vivenciada na rede

Educ. Soc., Campinas, vol. 30, n. 109, p. 1139-1166, set./dez. 2009

Disponível em <http://www.cedes.unicamp.br> 
municipal de ensino de Maringá, nos anos de 1991 e 1992, quando os professores passaram a ser "empresários" da educação ou "donos" da escola, sendo remunerados de acordo com a produtividade (Dias, 1995). Uma solução intermediária vem sendo adotada no Brasil, com o PDDE e o FUNDEF. Neste caso, a destinação de verbas é feita conforme o número de alunos, ou seja, é um mecanismo de financiamento per capita. As escolas competem entre si para atrair alunos, sob pena de perderem receitas e não poderem manter a sua estrutura de pessoal.

13. Para os teóricos neoliberais, como Milton Friedman, o mercado teria melhores condiçôes de promover a democracia, já que é de sua natureza administrar conflitos, construir consenso, promover harmonia social e garantir as liberdades individuais. Nesta perspectiva, ao estimular a proliferação de múltiplos centros competitivos, favorecendo a liberdade de escolha e decisão, conforme preferências individuais, o mercado torna a democracia mais eficaz.

14. Adhocacia é uma expressão cunhada por Alvin Tofler no contexto da simplificação dos processos burocráticos, das estruturas mais fluidas e da horizontalidade de poder de decisão.

15. Resultante do grau em que o produto/serviço atende aos padrôes estabelecidos, consideradas as demandas dos usuários.

16. A accountabitity é vista como categoria central no processo de reforma do sistema administrativo público. Refere-se à transparência do funcionamento administrativo e à responsabilização do sistema administrativo e da autoridade política pelas açôes e resultados da execução das políticas públicas. Ou seja, de acordo com Mozzicafreddo (2002, p. 9-10), a responsabilidade como conceito abrange, de um lado, o funcionamento do sistema administrativo e a obrigação de "prestar contas dos actos e decisões, cumprir prazos e procedimentos, desempenho profissional, comportamentos neutros e impessoais, etc. - e, por outro, afecta a produção (ou não) da confiança do cidadão na difusão da ética profissional e na realização eficaz dos programas públicos, como valor de legitimação do funcionamento da administração". O princípio de accountabitity é, portanto, "(...) utilizado como meio não apenas de controlar a utilização dos recursos públicos, segundo critérios e processo de apresentação de contas e resultados, mas também como maneira de estimular ganhos econômicos e eficiência com respeito aos recursos públicos (...)” (ibid., p. 11).

17. As APM se constituíram no principal instrumento de captação de recursos para o financiamento das atividades escolares, geralmente por meio de promoçōes, festas, concursos, cobrança de taxa de matrícula e mensalidades (contribuição "voluntária"), cantina, cobrança de multas por atraso na entrega de livros na biblioteca, aluguel de instalações para uso privado, possibilidade de exploração privada das escolas públicas, entre outros.

\section{Referências}

BARROSO, J. A "escolha da escola" como processo de regulação: integração e seleção social? In: BARROSO, J. (Org.). Escola pública: regulação, desregulação e privatização. Porto: Asa, 2003. p. 79-109. BRASIL. Decreto n. 2264 , de 27 de junho de 1997. Regulamenta a
Lei n. 9.424, de 24 de dezembro de 1996, no âmbito federal, e dá 
outras providências. Disponível em: <ftp://ftp.fnde.gov.br/web/fundef/ decretos/decreto_2264_270697.pdf.> Acesso em: 19 fev. 2008.

BRASIL. Decreto n. 6253, de 13 de novembro de 2007. Dispõe sobre o Fundo de Manutenção e Desenvolvimento da Educação Básica e de Valorização dos Profissionais da Educação (FUNDEB), regulamenta a Lei n. 11.494, de 20 de junho de 2007, e dá outras providências. Disponível em: <www.planalto.gov.br/ccivil_03/_Ato2007-2010/ 2007/Decreto/D6253.htm>. Acesso em: 19 fev. 2008.

BRASIL. Emenda Constitucional n. 14, de 13 de setembro de 1996. Lei que cria o FUNDEF (Fundo de Desenvolvimento do Ensino Fundamental e de Valorização do Magistério). Brasília, DF: Senado Federal, 1996.

BRASIL. Lei n. 9394, de 20 de dezembro de 1996. Estabelece a Lei de Diretrizes e Bases da Educação Nacional. Diário Oficial da União, Brasília, DF, seção I, p. 21.870, 22 dez. 1995.

BRASIL. Lei n. 9424, de 24 de dezembro de 1996. Dispõe sobre o Fundo de Manutenção e Desenvolvimento do Ensino Fundamental e de Valorização do Magistério. Disponível em: <www.planalto.gov.br/ ccivil_03/Leis/L9424.htm>. Acesso em: 19 fev. 2008.

BRASIL. Ministério da Administração Federal e da Reforma do Estado. Câmara de Reforma do Estado. Plano Diretor da Reforma do Aparelho do Estado. Brasília, DF: Presidência da República; Câmara de Reforma do Estado, 1995.

BRASIL. Ministério da Educação. Decreto n. 6094, de 24 de abril de 2007. Dispõe sobre a implementação do Plano de Metas Compromisso Todos pela Educação. Disponível em: <www.planalto.gov.br/ccivil_ 03/_Ato2007-2010/2007/Decreto/D6094.htm>. Acesso em: 19 fev. 2008.

BRASIL. Ministério da Educação. Planejamento politico-estratégico: 1995-1998. Brasília, DF: MEC, 1995.

BRASIL. Ministério da Educação. Projeto Acorda, Brasil, está na hora da escola!. Brasília, DF: MEC/SENAI/SESI/IEL, 1995.

BRASIL. Ministério da Educação. Fala Brasil. Disponível em: <http:/ /portal.mec.gov.br>. Acesso em: 16 jul. 2003. 
Reestruturação produtiva, reforma administrativa do Estado e gestão da educação

BRASIL. Ministério da Educação. Indice de Desenvolvimento da Educação Básica (IDEB). Brasília, DF: MEC/Inep, 2007. Disponível em: <http://portal.mec.gov.br>. Acesso em: 19 fev. 2008.

BRASIL. Ministério da Educação. O Plano de Desenvolvimento da Educação: razões, princípios e programas. Brasília DF: MEC/INEP, 2007. Disponível em: <http://portal.mec.gov.br/pde/>. Acesso em: 19 fev. 2008.

BRASIL. Ministério da Educação. Fundação Nacional de Desenvolvimento da Educação. Programa Dinheiro Direto na Escola: manual de instruções. Brasília, DF: MEC/FNDE/GPS/SEED, 2000.

BRASIL. Ministério da Educação. Instituto Nacional de Estudos e Pesquisas Educacionais (INEP). Sistema Nacional de Avaliação da Educação Básica - SAEB. Brasília DF: MEC/Inep, 1988. Disponível em: <www.inep.gov.br/saeb/default.htm>. Acesso em: 26 out. 2000.

BRASIL. Ministério da Educação. Instituto Nacional de Estudos e Pesquisas Educacionais (INEP). Exame Nacional do Ensino Médio - ENEM. Brasília, DF: MEC/INEP, 1998. Disponível em: <www.inep.gov.br/enem/ saiba.htm>. Acesso em: 26 out. 2000.

BRASIL. Ministério da Educação. Instituto Nacional de Estudos e Pesquisas Educacionais (IneP). Projeto Amigos da Escola. Brasília, DF: MEC/ INEP, 1999. Disponível em: <www.amigosdaescola.br>. Acesso em: 28 abr. 2001.

BRASIL. Ministério da Educação. Secretaria de Educação Fundamental. Parâmetros Curriculares Nacionais: introdução. Brasília, DF: MEC/ SEF, 1997. v. 1.

BRESSER PEREIRA, L.C. A Reforma do Estado dos anos 90: lógica e mecanismos de controle. Brasília, DF: Ministério da Administração Federal e Reforma do Estado, 1997. (Cadernos MARE da reforma do Estado; v. 1). 58p.

BRUNO, L.B. Poder e administração no capitalismo contemporâneo. In: Oliveira, D.A. Gestão democrática da educação: desafios contemporâneos. Petrópolis: Vozes, 1997. p. 15-45.

CARVALHO, E.J.G. Autonomia da gestão escolar: democratização e privatização, duas faces de uma mesma moeda. 2005. 235f. Tese 
(Doutorado) - Programa de Pós-Graduação em Educação, Universidade Metodista de Piracicaba, Piracicaba.

CHAUÍ, M. Fantasia da terceira via. Folha de S. Paulo, São Paulo, 19 dez. 1999. Caderno Mais, p. 7-10. Disponível em: <www.uol.com.br/ arquivosdafolha>. Acesso em: 18 maio 2001.

DIAS, R. (Org.). O público e o privado na educação: a experiência da privatização do ensino em Maringá e temas afins. Maringá: Secretaria Municipal de Educação, 1995.

FLEURY, A.C.C.; VARGAS, N. A organização do trabalho: uma abordagem interdisciplinar: sete estudos sobre a realidade brasileira. São Paulo: Atlas, 1983.

FONSECA, E.G. Globalização diminui as distâncias e lança o mundo na era das incertezas. Folha de S. Paulo, São Paulo, 2 nov. 1997. Caderno Especial.

FRIEDMAN, M. Capitalismo e liberdade. Trad. de Luciana Carli. 3. ed. São Paulo: Nova Cultural, 1988.

HARVEY, D. Condição pós-moderna. 9. ed. São Paulo: Loyola, 2000.

HOBSBAWN, E. A era dos extremos: o breve século XX - 1914-1991. 2. ed. São Paulo: Cia. das Letras, 1997.

LIMA, L.C. Modernização, racionalização e optimização: perspectivas neo-taylorianas na organização da administração escolar. Cadernos de Ciências Sociais, Braga, n. 14, p. 119-139, jan. 1994.

MOZZICAFREDDO, J. A responsabilidade e a cidadania na administração pública. Sociologia, Problemas e Práticas, Oeiras, n. 40, p. 9-22, 2002.

OSBORNE, D.; GOEBLER, T. Reinventando o governo: como o espírito empreendedor está transformando o setor público. 10. ed. Brasília, DF: MH Comunicações, 1998.

SILVA JUNIOR, J.R.; SGUISSARDI, V. Reforma da educação superior no Brasil: renúncia do Estado e privatização do público. Revista Portuguesa de Educação, Braga, v. 13, n. 2, p. 81-110, 2000. 
Reestruturação produtiva, reforma administrativa do Estado e gestão da educação

SENNETT, R. A corrosão do caráter: consequências pessoais do trabalho no novo capitalismo. 4. ed. Rio de Janeiro: Record, 2000.

SOUZA, S.Z.L.; OLIVEIRA, R.P. Políticas de avaliação da educação e quase-mercado no Brasil. Educação \& Sociedade, Campinas, v. 24, n. 84, p. 897-921, 2003. 